\title{
First laboratory study of air-sea gas exchange at hurricane wind speeds
}

\author{
K. E. Krall ${ }^{1}$ and B. Jähne $e^{1,2}$ \\ ${ }^{1}$ Institute of Environmental Physics, University of Heidelberg, Im Neuenheimer Feld 229, 69120 Heidelberg, Germany \\ ${ }^{2}$ Heidelberg Collaboratory for Image Processing, University of Heidelberg, Speyerer Straße 6, 69115 Heidelberg, Germany
}

Correspondence to: K. E. Krall (kerstin.krall@iup.uni-heidelberg.de)

Received: 2 October 2013 - Published in Ocean Sci. Discuss.: 5 November 2013

Revised: 27 February 2014 - Accepted: 13 March 2014 - Published: 23 April 2014

\begin{abstract}
In a pilot study conducted in October and November 2011, air-sea gas transfer velocities of the two sparingly soluble trace gases hexafluorobenzene and 1,4difluorobenzene were measured in the unique high-speed wind-wave tank at Kyoto University, Japan. This air-sea interaction facility is capable of producing hurricane strength wind speeds of up to $u_{10}=67 \mathrm{~m} \mathrm{~s}^{-1}$. This constitutes the first lab study of gas transfer at such high wind speeds. The measured transfer velocities $k_{600}$ spanned two orders of magnitude, lying between $11 \mathrm{cmh}^{-1}$ and $1180 \mathrm{cmh}^{-1}$ with the latter being the highest ever measured wind-induced gas transfer velocity. The measured gas transfer velocities are in agreement with the only available data set at hurricane wind speeds (McNeil and D'Asaro, 2007). The disproportionately large increase of the transfer velocities found at highest wind speeds indicates a new regime of air-sea gas transfer, which is characterized by strong wave breaking, enhanced turbulence and bubble cloud entrainment.
\end{abstract}

\section{Introduction}

Ocean regions, where strong winds usually occur, play an important role in global $\mathrm{CO}_{2}$ budgets (see Bates et al., 1998). Therefore, a better understanding of gas transfer at high wind speed conditions is essential. Field measurements of air-sea gas exchange velocities under hurricane wind speed conditions are sparse due to the difficulties of sampling under extreme wind conditions. During Hurricane Frances in 2004, McNeil and D'Asaro (2007) measured three transfer velocities of $\mathrm{O}_{2}$ using unmanned floats at wind speeds larger than $25 \mathrm{~m} \mathrm{~s}^{-1}$, with the highest wind speed being $50.4 \mathrm{~m} \mathrm{~s}^{-1}$.
High wind speeds are associated with the presence of breaking waves. Breaking waves enhance turbulence near the water surface and generate spray and bubble plumes, which increases gas fluxes (see for instance Monahan and Spillane, 1984, and Farmer et al., 1993). Breaking waves enhance gas transfer by several mechanisms: the water surface, across which gas is transferred, is enlarged by waves, and by breaking, waves enhance near-surface turbulence; bubbles and spray provide a limited, mostly short-lived volume of air or water associated with an additional surface area, over which gas transfer can occur (Memery and Merlivat, 1985); and by floating through air and water and bursting through the water surface, bubbles and spray enhance turbulent mixing near the water surface.

Wind-wave tanks provide an alternative to measurements in the field. All the inconveniences and dangers associated with measurements in the field during hurricane wind speed conditions are virtually non-existent in a lab setup. Until now, no gas exchange measurements had been performed in windwave tanks at free-stream velocities larger than $20 \mathrm{~m} \mathrm{~s}^{-1}$. The highest gas transfer velocity measured in fresh water is $180 \mathrm{~cm} \mathrm{~h}^{-1}$, at a wind speed close to $20 \mathrm{~ms}^{-1}$ (Komori and Shimada, 1995). Higher gas transfer velocities were only measured during the WABEX-93 experiment (Asher et al., 1995) in a freshwater surf pool without wind but with breaking waves. The highest measured gas transfer velocity measured in a laboratory, corrected to a Schmidt number of 600 , was $450 \mathrm{~cm} \mathrm{~h}^{-1}$ at a fractional whitecap coverage of 0.067 (Wanninkhof et al., 1995).

In late 2010 the first high-speed wind-wave facility became available at Kyoto University with free-stream wind speeds larger than $40 \mathrm{~ms}^{-1}$, opening up new experimental 
opportunities in the laboratory. It remains an open question, however, whether high wind speed conditions can be adequately simulated in laboratory facilities. This concerns mainly the spatial scale of breaking waves and the deep injection of bubbles with the resulting bubble dissolution flux pathway. Therefore, it makes sense to perform first a pilot study with limited effort to explore the feasibility of such experiments. The results of such a pilot study are reported in this paper.

\section{Air-sea gas transfer}

The net gas flux $j$ across the air-sea boundary is given as the product of the gas transfer velocity $k$ and the concentration difference as

$j=k \Delta c=k\left(c_{\mathrm{w}}-\alpha c_{\mathrm{a}}\right)$,

with the tracer's air- and water-side concentrations, $c_{\mathrm{a}}$ and $c_{\mathrm{w}}$, respectively, and the tracer's dimensionless solubility $\alpha$.

For a sparingly soluble tracer, a dependency of the transfer velocity $k$ on the water-sided friction velocity $u_{*}$, a measure for momentum input into the water, is commonly assumed in the form

$k \propto u_{*} S c^{-n}$,

with the tracer's dimensionless Schmidt number $S c=v / D$, the ratio between the kinematic viscosity of water $v$ and the tracer's diffusivity in water $D$. The Schmidt number exponent $n$ is two thirds in the case of a smooth water surface and one half for a rough and wavy surface. More thorough derivations of Eq. (2) can be found in Deacon (1977), Coantic (1986) and Jähne et al. (1989).

Equation (2) can be used to compare the transfer velocities of two tracers, $\mathrm{A}$ and $\mathrm{B}$, under the same conditions in the form of Schmidt number scaling,

$\frac{k_{\mathrm{A}}}{k_{\mathrm{B}}}=\left(\frac{S c_{\mathrm{A}}}{S c_{\mathrm{B}}}\right)^{-n}$.

On the ocean, the gas transfer velocity depends on many different factors such as wind speed, fetch, the presence of surface active material, and atmospheric stability. Wind speed has been identified as the main forcing factor. Many different empirical wind-speed-gas-transfervelocity parameterizations have been proposed in the last few decades, for instance Liss and Merlivat (1986), Wanninkhof (1992), Nightingale et al. (2000), McGillis et al. (2001), and Wanninkhof et al. (2009). These were all developed in the wind speed region below $15 \mathrm{~m} \mathrm{~s}^{-1}$, where most of them agree reasonably well with each other. Extending these parameterizations to wind speeds observed in a hurricane (see Fig. 1) paints a different picture with large deviations between the different parameterizations. At a wind speed of $50 \mathrm{~m} \mathrm{~s}^{-1}$, the deviations between the highest and the lowest

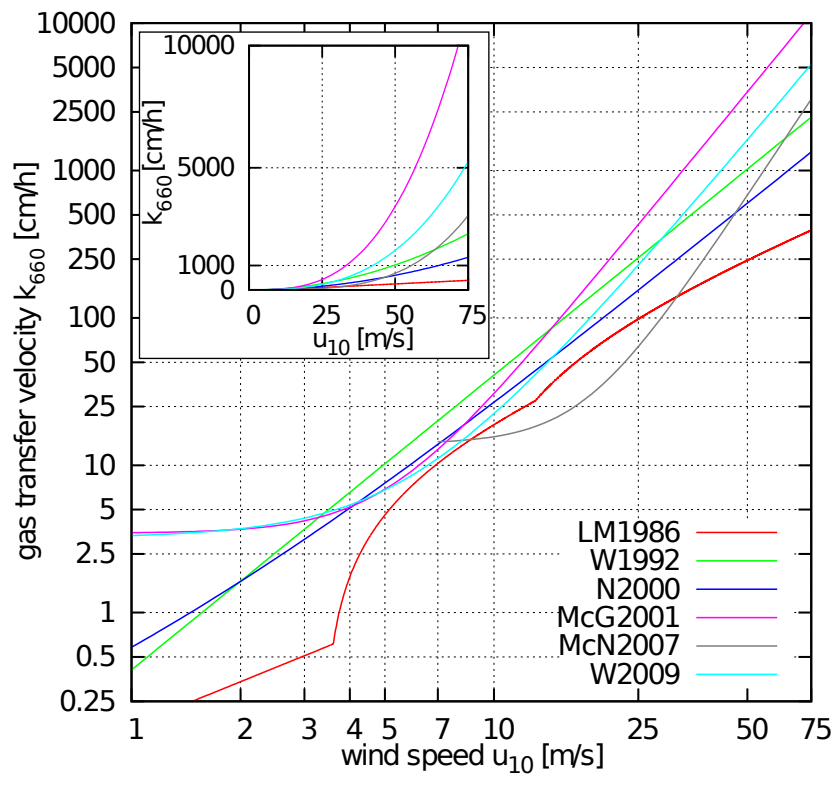

Fig. 1. Some commonly used gas-transfer-wind-speed parameterizations in a double logarithmic plot. The insert shows the same, but with linear axes. LM1986: Liss and Merlivat (1986), W1992: Wanninkhof (1992), N2000: Nightingale et al. (2000), McG2001: McGillis et al. (2001) and W2009: Wanninkhof et al. (2009). The parameterization by McNeil and D'Asaro (2007) (McN2007) is the only one developed for hurricane wind speeds.

predicted transfer velocity is more than one order of magnitude. This highlights the very limited applicability of gastransfer-wind-speed parameterizations in hurricane conditions. The only parameterization available for hurricane wind speeds by McNeil and D'Asaro (2007), who measured gas transfer velocities during Hurricane Frances, is also shown in Fig. 1.

At high wind speeds, breaking waves generate spray and bubbles. Gas transfer due to single bubbles is well studied experimentally (see for instance Mori et al., 2002, and Vasconcelos et al., 2002) as well as in models (see Memery and Merlivat, 1985). The impact of spray on the gas exchange velocity, however, has not been well studied. In most models of gas exchange at high wind speeds, the effects of breaking waves, spray and bubble clouds are combined into the breaking-wave-mediated transfer velocity, $k_{\mathrm{b}}$. Then it is assumed that the total gas transfer velocity $k$ can be split up into direct transfer through the surface $k_{\mathrm{s}}$ and the breakingwaves-mediated transfer velocity $k_{\mathrm{b}}$,

$k=k_{\mathrm{s}}+k_{\mathrm{b}}$,

(see Merlivat and Memery, 1983). Examples of parameterizations of $k_{\mathrm{b}}$ can be found in Keeling (1993) and Asher et al. (1996). More complex models are available (see for instance Woolf et al., 2007). All of the models of gas transfer at high wind speeds have in common that the gas exchange of a specific tracer not only depends on the Schmidt 
number but also on the solubility. Assuming tracers with the same Schmidt number, the transfer velocity due to breaking waves in these empirical models is higher for the tracer with the lower solubility.

\section{Method}

Classical evasion experiments (see for instance Jähne et al., 1979) were conducted in this study. In an evasion experiment, the decrease in concentration of a tracer, mixed into the water before the start of the experiment, is monitored over time. The simple approach described in Jähne et al. (1979) must be slightly modified and adapted to the Kyoto highspeed wind-wave tank to accommodate for water lost from the system due to spray.

Under the condition of a negligible air-side concentration $\alpha c_{\mathrm{a}} \approx 0$, and small solubility $\alpha$, as well as the choice of a tracer that is not in the water used to replace the water lost due to spray, the mass balance for a tracer on the water side is found to be

$V_{\mathrm{w}} \dot{c}_{\mathrm{w}}=-\left(A k+\dot{V}_{\mathrm{w}}\right) c_{\mathrm{w}}$.

In this equation, the mass of the tracer in the water is expressed using the water-side concentration $c_{\mathrm{w}}$. $A$ denotes the water surface area, $V_{\mathrm{w}}$ the total water volume, and $\dot{V}_{\mathrm{w}}$ is the rate of water inflow to replace water lost from the flume due to spray being blown out of the tank. The Kyoto high-speed wind-wave tank is an open facility, meaning fresh ambient air is blown over the water surface once and then removed from the system. Choosing a tracer that is not present in ambient air, the condition of a negligible air-side concentration $\alpha c_{\mathrm{a}} \approx 0$, can be met.

Equation (5) can be easily solved,

$c_{\mathrm{W}}(t)=c_{\mathrm{W}}(0) \cdot \exp \left(-\left(k \cdot \frac{A}{V_{\mathrm{w}}}+\frac{\dot{V}_{\mathrm{w}}}{V_{\mathrm{w}}}\right) \cdot t\right)$

with $c_{\mathrm{W}}(0)$ being the water-side concentration at time $t=0$.

The time constant $\tau$ of this equation is defined as

$\frac{1}{\tau}:=k \cdot \frac{A}{V_{\mathrm{w}}}+\frac{\dot{V}_{\mathrm{w}}}{V_{\mathrm{w}}}$

This time constant $\tau$ is acquired from an exponential fit of Eq. (6) to the time series of measured concentrations. The water volume $V_{\mathrm{w}}$, the water surface area $A$, as well as the leak rate $\lambda=\dot{V}_{\mathrm{w}} / V_{\mathrm{w}}$ are known or measured during an experiment. The transfer velocity can then be calculated as

$k=\left(\frac{1}{\tau}-\lambda\right) \cdot \frac{V_{\mathrm{w}}}{A}$.

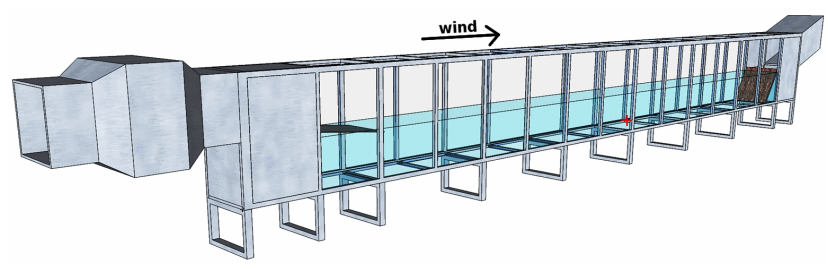

Fig. 2. Schematic view of the flume section of the Kyoto high-speed wind-wave tank. Not shown is the radial fan producing the wind (left side). The red cross marks the approximate sampling position.

\section{Experiments}

\subsection{Tracers}

The tracers were chosen such that their diffusivity in water, and thus their Schmidt numbers, were similar, while their solubility differed. Because UV absorption spectroscopy was used to measure tracer concentrations, tracers were chosen which exhibit a high extinction coefficient in the UV range as well as distinctly different spectra . To keep the mass balance described in Sect. 3 simple, the tracers were required to be absent from the ambient air, as well as absent in the tap water. The tracers chosen by these criteria were hexafluorobenzene (HFB) and 1,4-difluorobenzene (DFB). Table 1 lists properties of the tracers as well as carbon dioxide as a reference.

\subsection{Experimental setup}

\subsubsection{The Kyoto high-speed wind-wave tank}

The Kyoto high-speed wind-wave tank has a linear flume shape (see Fig. 2). The water flume is $80 \mathrm{~cm}$ wide, has a total length of $15.7 \mathrm{~m}$ with $12.9 \mathrm{~m}$ being exposed to the wind. The total height is $1.6 \mathrm{~m}$, with up to $0.8 \mathrm{~m}$ being filled with tap water. The wind is generated by a radial fan. The maximum wind speed that can be reached is $u_{10}=67.1 \mathrm{~m} \mathrm{~s}^{-1}$. Before the wind enters the air side of the tank, it passes through a honeycomb structure to minimize large eddies. The air is taken from the room surrounding the wind-wave tank and guided out of the building after it has been blown over the water.

There is an external water tank available that holds up to $7 \mathrm{~m}^{3}$ of water, which is connected to the wind-wave flume by two pipes: one pump draws the water out at the downwind end of the flume and into the water tank, and another pump draws the water out of the tank and into the upwind end of the wind-wave flume. For all lower wind speed settings, the amount of water coming out of the lab's water supply lines is sufficient to replace the water lost due to spray. At the highest wind speed setting, the external tank was used as a buffer to keep the water level constant inside the wind-wave tank. Trace gases can be mixed into the water by operating both 
Table 1. Molar mass, solubility, diffusivity in water and Schmidt numbers of the tracers hexafluorobenzene (HFB) and 1,4difluorobenzene (DFB) for a temperature of $20^{\circ} \mathrm{C}$. Also shown is $\mathrm{CO}_{2}$ for comparison.

\begin{tabular}{lrllr}
\hline Name & $\begin{array}{r}M \\
\mathrm{~g} \mathrm{~mol}^{-1}\end{array}$ & $\alpha$ at $20^{\circ} \mathrm{C}$ & $\begin{array}{l}D \\
10^{-5} \mathrm{~cm}^{2} \mathrm{~s}^{-1}\end{array}$ & $S c$ \\
\hline $\mathrm{HFB}$ & 186.1 & $1.0^{\mathrm{a}}$ & $0.736^{\mathrm{d}}$ & $1360^{\mathrm{e}}$ \\
$\mathrm{DFB}$ & 114.1 & $3.08^{\mathrm{b}}$ & $0.815^{\mathrm{d}}$ & $1225^{\mathrm{e}}$ \\
$\mathrm{CO}_{2}$ & 44.01 & $0.83^{\mathrm{c}}$ & $1.68^{\mathrm{f}}$ & $601^{\mathrm{f}}$ \\
\hline
\end{tabular}

a calculated from mole fraction solubility from Freire et al. (2005) and vapor pressure from Ambrose et al. (1990). ${ }^{b}$ Yaws and Yang (1992).

${ }^{c}$ Young (1981). ${ }^{d}$ Yaws (1995). ${ }^{\mathrm{e}}$ calculated from diffusion coefficients taken from Yaws (1995) and water viscosity taken from Kestin et al. (1987).

f Jähne et al. (1987).

pumps and thus cycling the water between the external tank and the wind-wave flume.

\subsubsection{Concentration measurement}

Tracer concentrations in the water were monitored using UV absorption spectroscopy. Water was sampled at a fetch of about $6.5 \mathrm{~m}$ at a water height of approximately $35 \mathrm{~cm}$ with a rate of 7 to $10 \mathrm{Lmin}^{-1}$. The approximate sampling location is marked in Fig. 2. Because air bubbles generated by breaking waves would have scattered the light out of the UV spectroscopic measuring cell, it was decided to not spectroscopically analyze the water directly, but to equilibrate the water with a small parcel of air first, and analyze this air. The water extraction and equilibration setup is shown in Fig. 3. A membrane equilibrator called an oxygenator (Jostra Quadrox manufactured by Maquet, Hirrlingen, Germany) was used to equilibrate the water with the air. Because of the large inner surface of the device in relation to its water volume, the time constant for gas equilibration is very fast. Measurements performed by Krall (2013, pp. 56-57) show that the response on a step concentration change of hexafluorobenzene has a time constant between 1.2 and $1.3 \mathrm{~min}$. Because of its higher solubility, the time constant for difluorobenzene should be even faster. Thus the time constant of the gas equilibrator is about five times faster than the shortest e-folding time of hexafluorobenzene gas exchange, which was $6.6 \mathrm{~min}$ at the highest wind speed. Therefore, the measured gas transfer velocities are not biased by a limited time constant of the gas equilibrator.

Air is cycled around the closed air loop at a rate of about $150 \mathrm{~mL} \mathrm{~min}^{-1}$. During the measurements, the valves were set such, that no outside air could enter or leave the air loop. During preparation of the experiment, the valves allowed sampling of ambient air to estimate the background. In addition, the water temperature was monitored.

The gas sampling cell is made of a $1 \mathrm{~m}$-long quartz glass tube with an inner diameter of $3 \mathrm{~mm}$. Light produced by a deuterium lamp enters the tube through a quartz glass lens

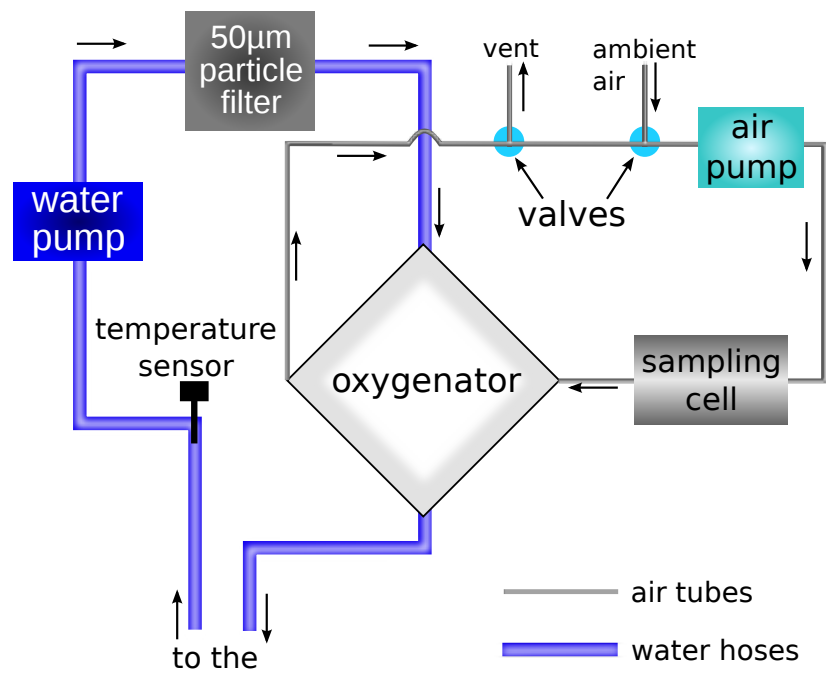

wind-wave-tank

Fig. 3. Gas extraction setup. Water pumped from the wind-wave tank is equilibrated with air using an oxygenator. The air is continuously cycled between the oxygenator and the UV-spectroscopic measuring cell. The valves allow background sampling and are closed during measurements.

with a focal length of $5 \mathrm{~cm}$ and a quartz glass window. It leaves the measuring cell through another quartz glass window and lens to be focused on a glass fiber. This glass fiber is connected to a UV spectrometer (Maya2000 Pro by Ocean Optics, Dunedin, USA). This spectrometer can resolve wavelengths from 190.5 to $294.1 \mathrm{~nm}$ with a resolution of approximately $0.05 \mathrm{~nm}$. About one spectrum was acquired per second.

During data evaluation, one absorbance value per tracer is calculated from each spectrum in a process described in detail in Krall (2013). Beer's law states that the absorbance $A$ of a tracer is directly proportional to the concentration in the measured air parcel, $c_{\mathrm{a}}$. According to Henry's law, the air-side concentration is proportional to the water-side concentration $c_{\mathrm{w}}$; thus $A \propto c_{\mathrm{a}} \propto c_{\mathrm{w}}$. Because only the change in concentration over time is relevant to measure the gas transfer velocity (see Eqs. 6 and 8), no absolute calibration that converts absorbance into the water-side concentrations is needed. Equation (6) can then be converted into the form

$\frac{c_{\mathrm{W}}(t)}{c_{\mathrm{W}}(0)}=\frac{A(t)}{A(0)}=\exp \left(-\frac{t}{\tau}\right)$,

with the time constant $\tau$ that is needed to calculate the gas transfer velocities (see Eq. 8).

\subsection{Experimental conditions}

A total of 21 experiments at nine different fixed wind speeds were performed. The wind generator's rotational frequency $f_{\text {fan }}$ was set and kept constant for each condition. The freestream wind speed $u_{\text {inf }}$, the air-sided friction velocity $u_{*}$ as 


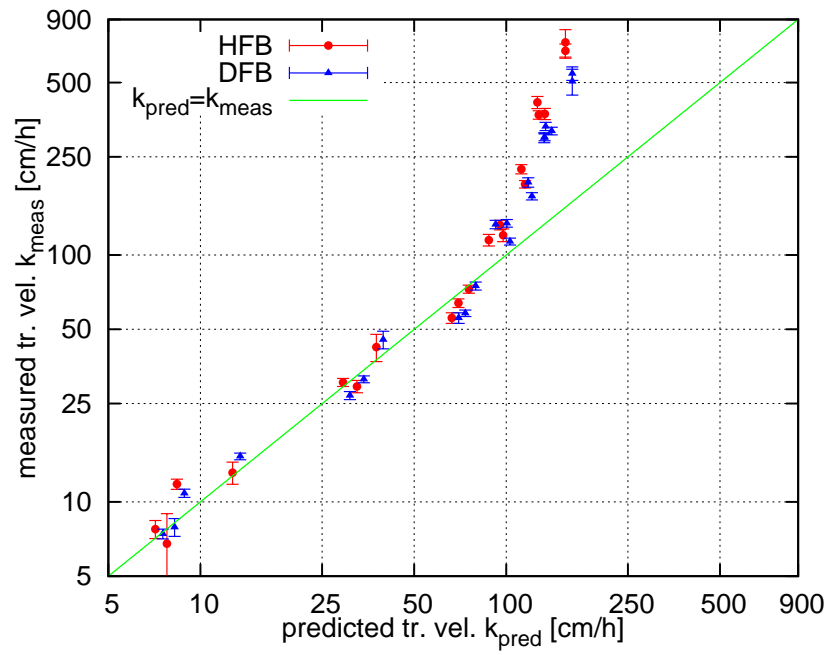

Fig. 4. Measured transfer velocities $k_{\text {meas }}$ for HFB and DFB as well as the transfer velocities $k_{\text {pred }}$ predicted by Eq. (2) in a double logarithmic plot.

well as the wind speed at a height of $10 \mathrm{~m} u_{10}$, which is commonly used as a reference, were not measured during the presented campaign, but taken from a table kindly provided by the Japanese colleagues. The wind speed at a height of $10 \mathrm{~m}$ $u_{10}$ was extrapolated from the measured friction velocity $u_{*}$ and free-stream wind speed using a logarithmic wind profile. Water height $h_{\mathrm{w}}$ was measured at the wind inlet before and after each experiment with no wind and no waves. Typically, both water height values differed by no more than $1 \%$. This ensured that the rate of inflowing water $\dot{V}_{\mathrm{w}}$ was equal to the amount of water lost due to spray as required by the method (see Sect. 3). The conditions used are listed in Table 2. Transfer velocities of both tracers were measured in parallel in each of the experiments, with the exception of one experiment at $f_{\text {fan }}=600$, where only the absorbance time series of DFB could be evaluated.

\section{Results}

\subsection{Comparison with gas exchange model and field measurements}

A total of 41 transfer velocities were measured, 21 of which for DFB and 20 for HFB. Figure 4 shows the measured transfer velocities for both tracers versus the transfer velocities predicted by Eq. (2). The momentum transfer resistance parameter $\beta$ was assumed to be 6.7 (see Krall, 2013). The Schmidt number exponent was chosen to be $n=0.5$ at medium to high wind speeds. However, to compensate for the smooth water surface visually observed at low fetches during the two lowest wind speeds of $7 \mathrm{~m} \mathrm{~s}^{-1}$ and $12.1 \mathrm{~m} \mathrm{~s}^{-1}$, the exponent was set to a value of 0.55 .

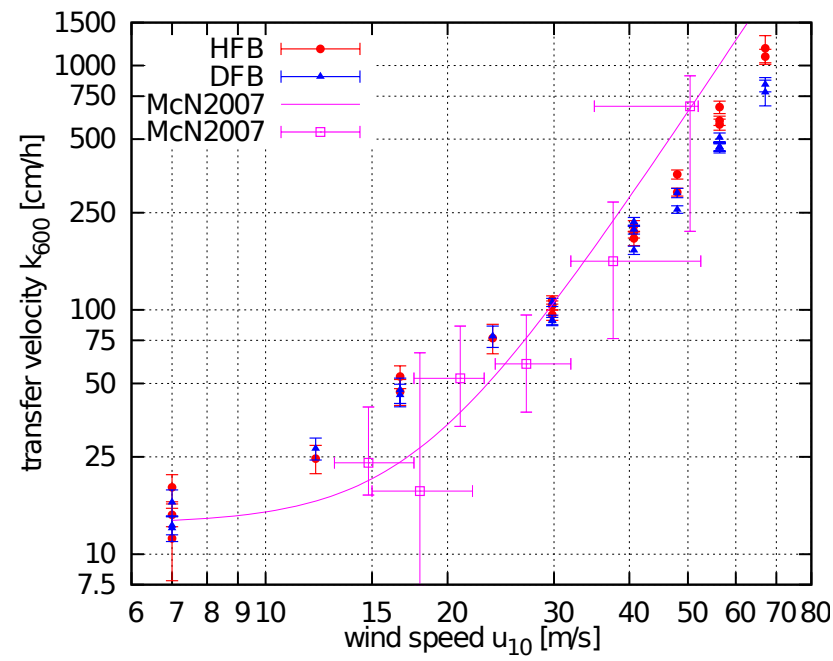

Fig. 5. Measured transfer velocities for HFB and DFB, compared to the data and parameterization by McNeil and D'Asaro (2007), all scaled to a Schmidt number of 600, in a double logarithmic plot.

For the low friction velocities of up to $u_{*}<6 \mathrm{~cm} \mathrm{~s}^{-1}$, which corresponds to a wind speed of $u_{10}<35 \mathrm{~m} \mathrm{~s}^{-1}$, and transfer velocities around $80 \mathrm{~cm} \mathrm{~s}^{-1}$, the measured transfer velocities agree well with the transfer model's prediction. At higher wind speeds, the measured transfer velocities exceed the ones expected from Eq. (2) by up to around $340 \%$ (HFB) and $220 \%$ (DFB).

Figure 5 shows the transfer velocities, scaled to a Schmidt number of 600 using Schmidt number scaling (Eq. 3) in comparison with the data by McNeil and D'Asaro (2007) acquired on the open ocean, including their proposed parameterization. Within the margin of errors, both data sets agree surprisingly well.

This does not mean that it is possible to transfer these laboratory data directly to the field. The conditions are too different: fresh water was used instead of sea water, the scales of the short-fetch waves in the laboratory are much smaller than at sea, and deep injection of bubbles and the resulting bubble dissolution flux pathway does not occur with a mean water depth of only $0.80 \mathrm{~m}$.

Strictly speaking, scaling to a Schmidt number of 600 is also not correct, because Schmidt number scaling only applies to the transfer across the free-water interface. The different bubble mediated processes scale in a different way, with the tracer's solubility becoming the second key parameter. It can be expected that the applied scaling somewhat underestimates the oxygen-nitrogen-based gas exchange measurements of McNeil and D'Asaro (2007), because these two gases have much lower solubility. Given the limited experimental data from the pilot experiment, it is still the best that can be done. The resulting uncertainty of this approach is probably not larger than the error bars of the field measurements from McNeil and D'Asaro (2007) (Fig. 5). 
Table 2. Experimental conditions used at the Kyoto high-speed wind-wave tank. $f_{\text {fan }}$ is the frequency of the wind-generating fan, $u_{*}$ is the friction velocity, $u_{\mathrm{inf}}$ denotes the free-stream velocity, and $u_{10}$ is the wind speed at $10 \mathrm{~m}$ height. $\dot{V}_{\mathrm{W}}$ is the leak rate. The number of repetitions of each of the conditions is labeled with $n$. One free-stream velocity $u_{\text {inf }}$ was not measured (n.m.).

\begin{tabular}{rrrrrrl}
\hline $\begin{array}{r}f_{\text {fan }} \\
\mathrm{rpm}\end{array}$ & $\begin{array}{r}u_{*} \\
\mathrm{~cm} \mathrm{~s}^{-1}\end{array}$ & $\begin{array}{r}u_{\text {inf }} \\
\mathrm{m} \mathrm{s}^{-1}\end{array}$ & $\begin{array}{r}u_{10} \\
\mathrm{~m} \mathrm{~s}^{-1}\end{array}$ & $\begin{array}{r}\dot{V}_{\mathrm{w}} \\
\mathrm{Lin}^{-1}\end{array}$ & $n$ & notes \\
\hline 100 & 0.836 & 4.72 & 7.0 & 0 & 3 & \\
150 & 1.50 & 10.36 & 12.1 & 0 & 1 & \\
200 & 2.34 & 10.29 & 16.7 & 0 & 2 & \\
250 & 3.10 & n.m. & 23.75 & 0 & 1 & \\
300 & 5.19 & 16.26 & 29.8 & 0 & 3 & \\
400 & 7.24 & 22.17 & 40.7 & 0 & 3 & \\
500 & 8.23 & 28.47 & 48.0 & 3.5 & 2 & \\
600 & 9.37 & 34.75 & 56.4 & 14.5 & 4 & only three experiments evaluable for HFB \\
800 & 11.5 & 43.29 & 67.1 & 192 & 2 & $V_{\text {w decreased, external tank used }}$ \\
\hline
\end{tabular}

One important conclusion can be drawn nevertheless: if one of the dominant pathways for gas transfer induced by breaking waves were missing in the laboratory experiment, the gas transfer velocities measured there would be significantly smaller than those measured in the field. The experimental data indicate that this is not the case. This encourages further, more detailed wind-wave tunnel experiments, because it is likely that the more important processes are adequately captured in the Kyoto high-speed wind-wave tank. More specifically, this suggests - but still needs to be proven - that the bubble dissolution flux pathway may be not the dominant mechanism at these high wind speeds.

\subsection{Enhancement at highest wind speeds}

Vlahos and Monahan (2009) and Vlahos et al. (2011) present measured transfer velocities of dimethyl sulfide (DMS), which show a decrease in the gas transfer velocity when bubble clouds are present at high wind speeds. For both tracers used in this study, this decrease was not observed. Up to a wind speed of $35 \mathrm{~m} \mathrm{~s}^{-1}$, the gas transfer velocity is roughly proportional to $u_{10}^{1.1}$. For higher wind speeds, the proportionality changes to $k \propto u_{10}^{3}$ for DFB and $k \propto u_{10}^{3.6}$ for HFB (see Fig. 6). This clearly indicates the start of a new regime of air-sea gas exchange starting at around $35 \mathrm{~m} \mathrm{~s}^{-1}$. In order to compare the theory of Vlahos with our experimental data and to estimate the DMS transfer velocity, it would be necessary to know the total surface of bubbles submerged by breaking waves in relation to the surface area of the facility. These data are not available from this pilot experiment. All that can be said is that difluorobenzene and hexafluorobenzene are flat symmetrical molecules with certainly a much lower surface activity than DMS. Thus it is neither possible to verify nor to dismiss the theory of Vlahos.

At the highest wind speeds, the transfer velocity of HFB increases stronger than the one of DFB, as indicated by the different slopes in Fig. 6. To quantify this, an enhancement

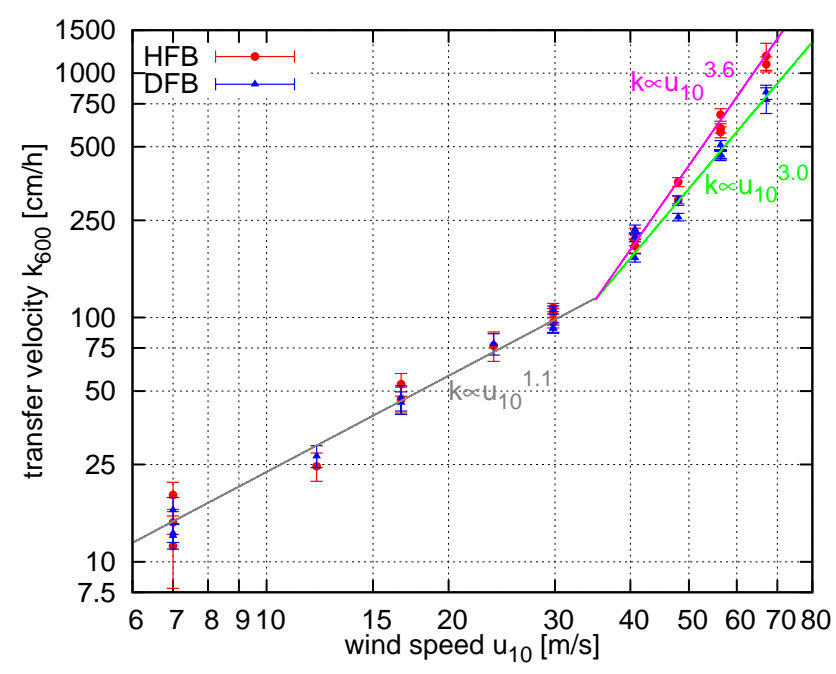

Fig. 6. Measured transfer velocities for HFB and DFB scaled to a Schmidt number of 600 . Also shown are lines indicating proportionalities of the transfer velocities $k_{600}$ to $u_{10}^{x}$ with $x$ depending on the wind speed range and the tracer.

factor $E_{\mathrm{f}}$ can be defined by

$E_{\mathrm{f}}:=\frac{k_{600, \mathrm{HFB}}-k_{600, \mathrm{DFB}}}{k_{600, \mathrm{DFB}}} \cdot 100 \%$.

Figure 7 shows the enhancement factor $E_{\mathrm{f}}$, averaged on a condition basis. Up to a wind speed of around $40 \mathrm{~ms}^{-1}$, no enhancement is observed. Above $40 \mathrm{~m} \mathrm{~s}^{-1}$, however, the transfer velocity of HFB is up to $40 \%$ larger than that of DFB with a clear wind speed dependence. This enhancement is expected from bubble models (see Sect. 2), with the less soluble tracer HFB ( $\alpha=1.0$ at $20^{\circ} \mathrm{C}$ ) having larger transfer velocities than the slightly higher soluble tracer DFB $(\alpha=3.08$ at $20^{\circ} \mathrm{C}$ ).

The tracers used in this pilot study span only a small fraction of the Schmidt number - solubility parameter space, (Fig. 8). In particular, gases with low solubilities are missing 


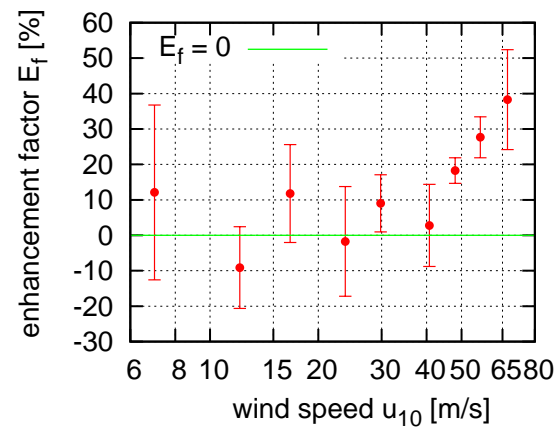

Fig. 7. Mean enhancement of the transfer velocity of HFB over that of DFB, both scaled to a Schmidt number of 600 . An $E_{\mathrm{f}}$ of 0 means no enhancement.

where bubble-mediated gas transfer can be expected to be even higher. In addition, no bubble density spectra are available. Therefore, a more detailed analysis would make no sense and is omitted in this paper. With such limited data, any model on bubble-mediated gas transfer can be fitted to the data (Krall, 2013) with the result that no conclusive statements are possible. In particular any extrapolation to a gas with lower or higher solubility than the tracers used in this study is highly speculative and very likely incorrect.

\section{Conclusions and outlook}

The transfer velocities at hurricane strength wind speeds were found to be extremely high. The measured transfer velocities were found to be in agreement with the only other data set of gas transfer at extreme wind speeds (McNeil and D'Asaro, 2007). In wind speeds higher than around $35-40 \mathrm{~m} \mathrm{~s}^{-1}$, where frequent large-scale wave breaking with bubble entrainment and spray generation occurs, the correlation between gas transfer velocities and wind speed was found to become steeper, indicating a new regime of airsea gas exchange. The steepness of the relationship between the gas transfer velocity and the wind speed could be linked to the solubility of the tracer. The lower the solubility, the higher the transfer velocities measured.

The results of this pilot study confirm that it is possible to measure realistic air-sea gas exchange velocities in a windwave tank at hurricane wind speeds with the method described in this paper. However, due to the aforementioned limitations in solubility and Schmidt number, a physical interpretation as well as physics-based modeling will have to be suspended until detailed measurements of bubble and spray densities and of turbulence have been conducted. For a detailed and robust parameterization, it is also required to perform experiments with many tracers simultaneously, which cover the largest possible range of solubilities and Schmidt numbers. If these requirements are met, it would be highly possible to estimate gas transfer velocities at sea from laboratory measurements.

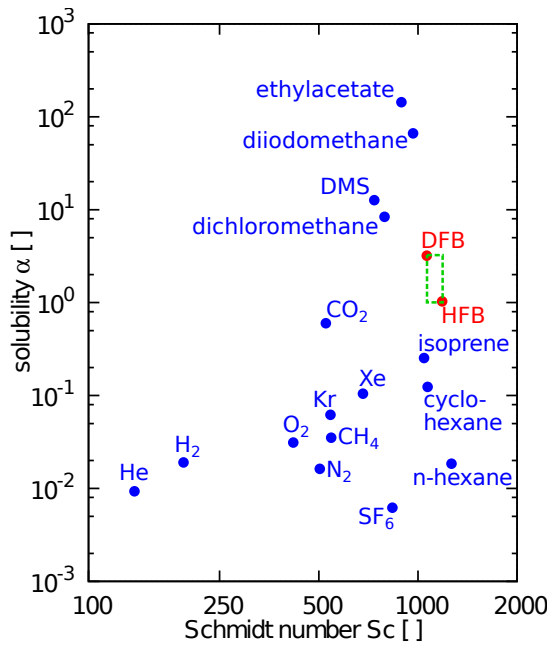

Fig. 8. Double logarithmic Schmidt number-solubility diagram of some environmentally important tracers for a temperature of $25^{\circ} \mathrm{C}$. The tracers used in this study, hexafluorobenzene (HFB) and 1,4-difluorobenzene (DFB), cover a very limited parameter range, marked by the dashed green rectangle.

Acknowledgements. We cordially thank all members of the Environmental Fluids and Thermal Engineering Lab at Kyoto University under the lead of S. Komori for providing excellent working conditions and assistance during preparation and measurements, as well as N. Takagaki and K. Iwano for making wind speed, friction velocity and free-stream velocity data available. We are grateful for the assistance of W. Mischler during all stages of the measurements. Constructive comments of two anonymous reviewers as well as our editor D. Woolf helped to improve this paper. The financial support for this project by Mobility Networks within the Institutional Strategy ZUK49 "Heidelberg: Realizing the Potential of a Comprehensive University" and by the German Federal Ministry of Education and Research (BMBF) joint project "Surface Ocean Processes in the Anthropocene" (SOPRAN, FKZ $03 \mathrm{~F} 0611 \mathrm{~F}$ ) is gratefully acknowledged.

Edited by: D. Woolf

\section{References}

Ambrose, D., Ewing, M. B., Ghiassee, N. B., and Sanchez Ochoa, J. C.: The ebulliometric method of vapour pressure measurement: vapour pressures of benzene, hexafluorobenzene, and naphthalene, J. Chem. Thermodyn., 22, 589-605, 1990.

Asher, W. E., Higgins, B. J., Karle, L. M., Farley, P. J., Sherwood, C. R., Gardiner, W. W., Wanninkhof, R., Chen, H., Lantry, T., Steckley, M., Monahan, E. C., Wang, Q., and Smith, P. M.: Measurement of gas transfer, whitecap coverage, and brightness temperature in a surf pool: an overview of WABEX-93, in: Air-Water Gas Transfer, Selected Papers, 3rd Intern. Symp. on Air-Water Gas Transfer, edited by: Jähne, B. and Monahan, E., 207-216, AEON, Hanau, 1995.

Asher, W. E., Karle, L. M., Higgins, B. J., Farley, P. J., Monahan, E. C., and Leifer, I. S.: The influence of bubble plumes on air- 
seawater gas transfer velocities, J. Geophys. Res., 101, 1202712041, 1996.

Bates, N. R., Knap, A. H., and Michaels, A. F.: Contribution of hurricanes to local and global estimates of air-sea exchange of $\mathrm{CO}_{2}$, Nature, 395, 58-61, 1998.

Coantic, M.: A model of gas transfer across air-water interfaces with capillary waves, J. Geophys. Res., 91, 3925-3943, 1986.

Deacon, E. L.: Gas transfer to and across an air-water interface, Tellus, 29, 363-374, 1977.

Farmer, D. M., McNeil, C. L., and Johnson, B. D.: Evidence for the importance of bubbles in increasing air-sea gas flux, Nature, 361, 620-623, 1993.

Freire, M. G., Razzouk, A., Mokbel, I., Jose, J., Marrucho, I. M., and Coutinho, J. A. P.: Solubility of hexafluorobenzene in aqueous salt solutions from (280 to 340) K, J. Chem. Eng. Data, 50, 237-242, 2005.

Jähne, B., Münnich, K. O., and Siegenthaler, U.: Measurements of gas-exchange and momentum-transfer in a circular wind-water tunnel, Tellus, 31, 321-329, 1979.

Jähne, B., Heinz, G., and Dietrich, W.: Measurement of the diffusion coefficients of sparingly soluble gases in water, J. Geophys. Res., 92, 10767-10776, 1987.

Jähne, B., Libner, P., Fischer, R., Billen, T., and Plate, E. J.: Investigating the transfer process across the free aqueous boundary layer by the controlled flux method, Tellus, 41B, 177-195, 1989.

Keeling, R. F.: On the role of large bubbles in air-sea gas exchange and supersaturation in the ocean, J. Marine Res., 51, 237-271, 1993.

Kestin, J., Sokolov, M., and Wakeham, W. A.: Viscosity of liquid water in the range $-8^{\circ} \mathrm{C}$ to $150^{\circ} \mathrm{C}$, J. Phys. Chem. Ref. Data, 7, 941-948, 1978.

Komori, S. and Shimada, T.: Gas transfer across a wind-driven airwater interface and the effects of sea water on $\mathrm{CO}_{2}$ transfer, in: Air-Water Gas Transfer, Selected Papers, 3rd Intern. Symp. on Air-Water Gas Transfer, edited by: Jähne, B. and Monahan, E., 553-569, AEON, Hanau, 1995.

Krall, K. E.: Laboratory Investigations of Air-Sea Gas Transfer under a Wide Range of Water Surface Conditions, Ph.D. Thesis, available at: http://www.ub.uni-heidelberg.de/archiv/14392 (last access: 14 April 2014), Institut für Umweltphysik, Fakultät für Physik und Astronomie, University of Heidelberg, 2013.

Liss, P. S. and Merlivat, L.: Air-sea gas exchange rates: Introduction and synthesis, in: The role of air-sea exchange in geochemical cycling, edited by: Buat-Menard, P., 113-129, Reidel, Boston, MA, 1986.

McGillis, W. R., Edson, J. B., Hare, J. E., and Fairall, C. W.: Direct covariance air-sea $\mathrm{CO}_{2}$ fluxes, J. Geophys. Res., 106, 1672916745, 2001.

McNeil, C. and D'Asaro, E.: Parameterization of air sea gas fluxes at extreme wind speeds, J. Marine Syst., 66, 110-121, 2007.

Memery, L. and Merlivat, L.: Modelling of gas flux through bubbles at the air-water interface, Tellus B, 37, 272-285, 1985.
Merlivat, L. and Memery, L.: Gas exchange across an air-water interface: experimental results and modeling of bubble contribution to transfer, J. Geophys. Res., 88, 707-724, 1983.

Monahan, E. C. and Spillane, M. C.: The role of whitecaps in airsea gas exchange Gas transfer at water surfaces, in: Gas transfer at water surfaces, edited by: Brutsaert, W. and Jirka, G. H., 495503, 1984.

Mori, N., Imamura, M., and Yamamoto, R.: An experimental study of bubble mediated gas exchange for a single bubble, in: Gas Transfer at Water Surfaces, edited by: Donelan, M. A., Drennan, W. M., Saltzman, E. S., and Wanninkhof, R., Geophysical Monograph, 127, 311-313, 2002.

Nightingale, P. D., Malin, G., Law, C. S., Watson, A. J., Liss, P. S., Liddicoat, M. I., Boutin, J., and Upstill-Goddard, R. C.: In situ evaluation of air-sea gas exchange parameterization using, novel conservation and volatile tracers, Glob. Biogeochem. Cy., 14, 373-387, 2000.

Vasconcelos, J. M. T., Orvalho, S. P., and Alves, S. S.: Gas-liquid mass transfer to single bubbles: Effect of surface,contamination, AIChE Journal, 48, 1145-1154, 2002.

Vlahos, P. and Monahan, E. C.: A generalized model for the air-sea transfer of dimethyl sulfide at high wind speeds, Geophys. Res. Lett., 36, L21605, doi:10.1029/2009GL040695, 2009.

Vlahos, P., Monahan, E. C., Huebert, B. J., and Edson, J. B.: Winddependence of DMS transfer velocity: Comparison of model with recent southern ocean observations, in: Gas Transfer at Water Surfaces 2010, edited by: Komori, S., McGillis, W., and Kurose, R., 313-321, 2011.

Wanninkhof, R.: Relationship between wind speed and gas exchange over the ocean, J. Geophys. Res., 97, 7373-7382, doi:10.1029/92JC00188, 1992.

Wanninkhof, R., Asher, W., and Monahan, E.: The influence of bubbles on air-water gas exchange: results from gas transfer experiments during WABEX-93, in: Air-Water Gas Transfer, Selected Papers, 3rd Intern. Symp. on Air-Water Gas Transfer, edited by: Jähne, B. and Monahan, E., 239-254, AEON, Hanau, 1995.

Wanninkhof, R., Asher, W. E., Ho, D. T., Sweeney, C., and McGillis, W. R.: Advances in quantifying air-sea gas exchange and environmental forcing, Annu. Rev. Mar. Sci., 1, 213-244, 2009.

Woolf, D., Leifer, I., Nightingale, P., Rhee, T., Bowyer, P., Caulliez, G., de Leeuw, G., Larsen, S., Liddicoat, M., Baker, J., and Andreae, M.: Modelling of bubble-mediated gas transfer: Fundamental principles and,a laboratory test, J. Marine Syst., 66, 7191, 2007.

Yaws, C. L.: Handbook of Transport Property Data, Gulf Publishing Company, 1995.

Yaws, C. L. and Yang, H.-C.: Henry's law constant for compound in water, in: Thermodynamic and Physical Property Data, edited by: Yaws, C. L., Gulf Publishing Company, 181-206, 1992.

Young, C. L. (Ed.): IUPAC Solubility Data Series, Vol. 8, Oxides of Nitrogen, Pergamon Press, Oxford, England, 1981. 


\section{Appendix A}

\section{Measured transfer velocities}

Table A1 summarizes all measured experimental data: friction velocity, wind speed, mean water temperature, as well as both tracer's transfer velocities and Schmidt numbers.

Table A1. Transfer velocities $k$ (not scaled to $S c=600$ ) measured in the Kyoto high-speed wind-wave tank for tracers 1,4-difluorobenzene (DFB) and hexafluorobenzene (HFB) and their respective uncertainties $\Delta k$. "n.m." means not measured. The wind speed $u_{10}$ and watersided friction velocity $u_{*}$, kindly provided by the Japanese colleagues, are also given. $T$ denotes the mean water temperature during the measurement. Schmidt numbers $S c$ of the tracers at this temperature are also shown.

\begin{tabular}{|c|c|c|c|c|c|c|c|c|c|c|}
\hline $\begin{array}{l}\text { Date } \\
\text { (yyyy/mm/dd) }\end{array}$ & $\begin{array}{r}u_{*, \mathrm{w}} \\
\mathrm{cm} \mathrm{s}^{-1}\end{array}$ & $\begin{array}{r}u_{10} \\
\mathrm{~m} \mathrm{~s}^{-1}\end{array}$ & $\begin{array}{r}k_{\mathrm{HFB}} \\
\mathrm{cm} \mathrm{h}^{-1}\end{array}$ & $\begin{array}{l}\Delta k_{\mathrm{HFB}} \\
\mathrm{cm} \mathrm{h}^{-1}\end{array}$ & $\begin{array}{r}k_{\mathrm{DFB}} \\
\mathrm{cm} \mathrm{h}^{-1}\end{array}$ & $\begin{array}{l}\Delta k_{\mathrm{DFB}} \\
\mathrm{cm} \mathrm{h}^{-1}\end{array}$ & $\begin{array}{c}T \\
{ }^{\circ} \mathrm{C}\end{array}$ & $S c_{\mathrm{HFB}}$ & $S c_{\mathrm{DFB}}$ & $n$ \\
\hline $2011 / 10 / 27$ & 9.38 & 56.4 & 369.5 & 14.8 & 332.1 & 12.8 & 17.5 & 1555 & 1403 & 0.5 \\
\hline $2011 / 10 / 28$ & 7.25 & 40.7 & 120.4 & 7.2 & 113.5 & 3.6 & 17.1 & 1590 & 1434 & 0.5 \\
\hline $2011 / 10 / 28$ & 9.38 & 56.4 & 415.3 & 23.3 & 299.2 & 14.0 & 17.1 & 1590 & 1434 & 0.5 \\
\hline $2011 / 10 / 31$ & 2.34 & 16.7 & 29.35 & 1.67 & 31.40 & 1.00 & 18.3 & 1489 & 1344 & 0.5 \\
\hline $2011 / 10 / 31$ & 8.23 & 48.0 & 222.8 & 9.4 & 196.9 & 8.6 & 17.5 & 1555 & 1403 & 0.5 \\
\hline 2011/11/02 & 5.19 & 29.8 & 72.77 & 2.75 & 74.86 & 2.8 & 19.9 & 1367 & 1234 & 0.5 \\
\hline 2011/11/02 & 8.23 & 48.0 & 193.6 & 6.7 & 173.0 & 5.8 & 18.5 & 1473 & 1329 & 0.5 \\
\hline 2011/11/04 & 0.84 & 7.0 & 11.80 & 0.56 & 10.84 & 0.42 & 19.5 & 1396 & 1260 & 0.55 \\
\hline 2011/11/04 & 9.38 & 56.4 & 373.1 & 19.5 & 318.1 & 11.4 & 19.2 & 1419 & 1280 & 0.5 \\
\hline 2011/11/08 & 5.19 & 29.8 & 63.86 & 2.58 & 58.13 & 1.75 & 17.0 & 1598 & 1442 & 0.5 \\
\hline 2011/11/10 & 11.5 & 67.1 & 726.2 & 92.6 & 505.3 & 60.7 & 17.25 & 1577 & 1422 & 0.5 \\
\hline $2011 / 11 / 11$ & 9.38 & 56.4 & n.m. & n.m. & 299.9 & 9.7 & 17.25 & 1577 & 1422 & 0.5 \\
\hline 2011/11/14 & 0.84 & 7.0 & 6.77 & 2.18 & 7.90 & 0.65 & 17.0 & 1598 & 1442 & 0.55 \\
\hline $2011 / 11 / 15$ & 7.25 & 40.7 & 132.4 & 5.9 & 134.7 & 4.8 & 16.2 & 1671 & 1507 & 0.5 \\
\hline 2011/11/16 & 2.34 & 16.7 & 30.5 & 1.1 & 26.98 & 1.0 & 14.5 & 1837 & 1657 & 0.5 \\
\hline 2011/11/16 & 7.25 & 40.7 & 114.9 & 6.2 & 133.1 & 5.3 & 13.25 & 1973 & 1779 & 0.5 \\
\hline 2011/11/17 & 1.50 & 12.1 & 13.1 & 1.4 & 15.29 & 0.48 & 14.1 & 1880 & 1695 & 0.55 \\
\hline $2011 / 11 / 17$ & 3.10 & 23.7 & 42.3 & 5.3 & 45.37 & 3.71 & 13.3 & 1967 & 1774 & 0.5 \\
\hline $2011 / 11 / 18$ & 0.84 & 7.0 & 7.75 & 0.65 & 7.42 & 0.34 & 14.15 & 1874 & 1690 & 0.55 \\
\hline 2011/11/19 & 5.19 & 29.8 & 55.6 & 2.8 & 55.59 & 2.8 & 15.2 & 1766 & 1593 & 0.5 \\
\hline $2011 / 11 / 19$ & 11.5 & 67.1 & 671.7 & 45.0 & 543.6 & 34.2 & 17.25 & 1577 & 1422 & 0.5 \\
\hline
\end{tabular}

